\title{
Engaging Māori in biobanking and genomic research: a model for biobanks to guide culturally informed governance, operational, and community engagement activities
}

\author{
Angela Beaton, $\mathrm{PhD}^{1}$, Maui Hudson, $\mathrm{BHSc} \mathrm{MHSc}^{2}$, Moe Milne, RPN ${ }^{3}$, Ramari Viola Port, $\mathrm{PhD}^{4}$, \\ Khyla Russell, PhD5 , Barry Smith, PhD', Valmaine Toki, LLM, PhD², Lynley Uerata, $\mathrm{MA}^{2}$, \\ Phillip Wilcox, $\mathrm{PhD}^{7}$, Karen Bartholomew, $\mathrm{MBChB} \mathrm{MPH}^{8}$ and Helen Wihongi, $\mathrm{PhD}^{8}$
}

Purpose: He Tangata Kei Tua, a relationship model for biobanks, was developed to facilitate best practice in addressing Māori ethical concerns by guiding culturally informed policy and practice for biobanks in relation to governance, operational, and community engagement activities.

Methods: The model is based on key issues of relevance to Māori that were identified as part of the Health Research Council of New Zealand-funded research project, Te Mata Ira (2012-2015).

Results: This project identified Māori perspectives on biobanking and genetic research, and along with tikanga Māori it developed cultural guidelines for ethical biobanking and genetic research involving biospecimens. The model draws on a foundation of mātauranga (Indigenous knowledge) and tikanga Māori (Māori protocols and practices) and will be useful for biobanks, researchers, ethics committee members, and those who engage in consultation or advice about biobanking in local, regional, national, or international settings.

Conclusion: This article describes the model and considers the policy and practice implications for biobanks seeking to address Māori ethical concerns. Although the model has focused on Māori aspirations in the New Zealand context, it provides a framework for considering cultural values in relation to other community or indigenous contexts.

Genet Med advance online publication 15 September 2016

Key Words: biobanking; genomic research; governance; Indigenous; Māori

\section{INTRODUCTION}

The establishment of well-managed and governed biobanks is necessary for the translation of medical research into clinical benefits. Biobanks store tissues, cells, and other derived products, most commonly for future unspecified use, to improve the future health status of populations. ${ }^{1}$ Genomic research is being rapidly integrated into clinical practice. ${ }^{2}$ This research is cutting-edge, innovative, and even paradigm-shifting; therefore, it is important that it not perpetuate health inequalities by excluding populations from sharing in the benefits of genomic medicine advances ${ }^{3}$ or create opportunities for cultural misunderstanding. ${ }^{4}$ This article examines the role and value of biobanks within New Zealand. Based on key issues identified by Māori informants and Iwi (tribal groups) and drawing on a foundation of mātauranga (Indigenous knowledge) and tikanga Māori (Māori protocols and practices), it proposes a relationship model for biobanks that may be operationalized to guide culturally informed biobank policy and practice (see Figure 1).

In practice, a biobank is an organized collection of biospecimens used for health research. The Organization for Economic Cooperation and Development definition specifically describes two components of a biobank: human biological materials and/or genetic information generated from their analysis and extensive associated demographic and health information. ${ }^{5-8}$ Common features of biobanks include: (i) an ongoing and open-ended nature, which often involves unspecified future research that challenges the traditional practice of informed consent; 9 (ii) biospecimens and data that remain potentially reidentifiable, even if they are coded $;{ }^{10}$ and (iii) a focus on the common good that may be more concerned with future public benefit than individual benefit for the participants themselves. ${ }^{11}$ Currently, there is often no direct or immediate benefit to individual donors.

Biobanks are becoming larger, with a move toward collaborative biobank networks for national and international sharing and virtual banks. ${ }^{12}$ There is also an international move toward collocating or integrating diagnostic and research laboratories to facilitate clinical application and translation of research. The collection and coordination of tissue samples for future research in New Zealand have largely been ad hoc, often arising from individual studies. The use of more formal biobanks is likely to increase as efforts are made to reduce the costs associated with

${ }^{1}$ Waikato Institute of Technology, Hamilton, New Zealand; ${ }^{2}$ University of Waikato, Hamilton, New Zealand; ${ }^{3}$ DipTeaching, Te Moemoea Ltd, Moerewa, New Zealand; Independent researcher, New Zealand; ${ }^{5}$ Otago Polytechnic, Otago, New Zealand; ${ }^{6}$ Lakes District Health Board, Rotorua, New Zealand; ${ }^{7}$ University of Otago, Otago, New Zealand; ${ }^{8}$ Waitemata District Health Board, Westlake, New Zealand. Correspondence: Angela Beaton (Angela.Beaton@wintec.ac.nz) 


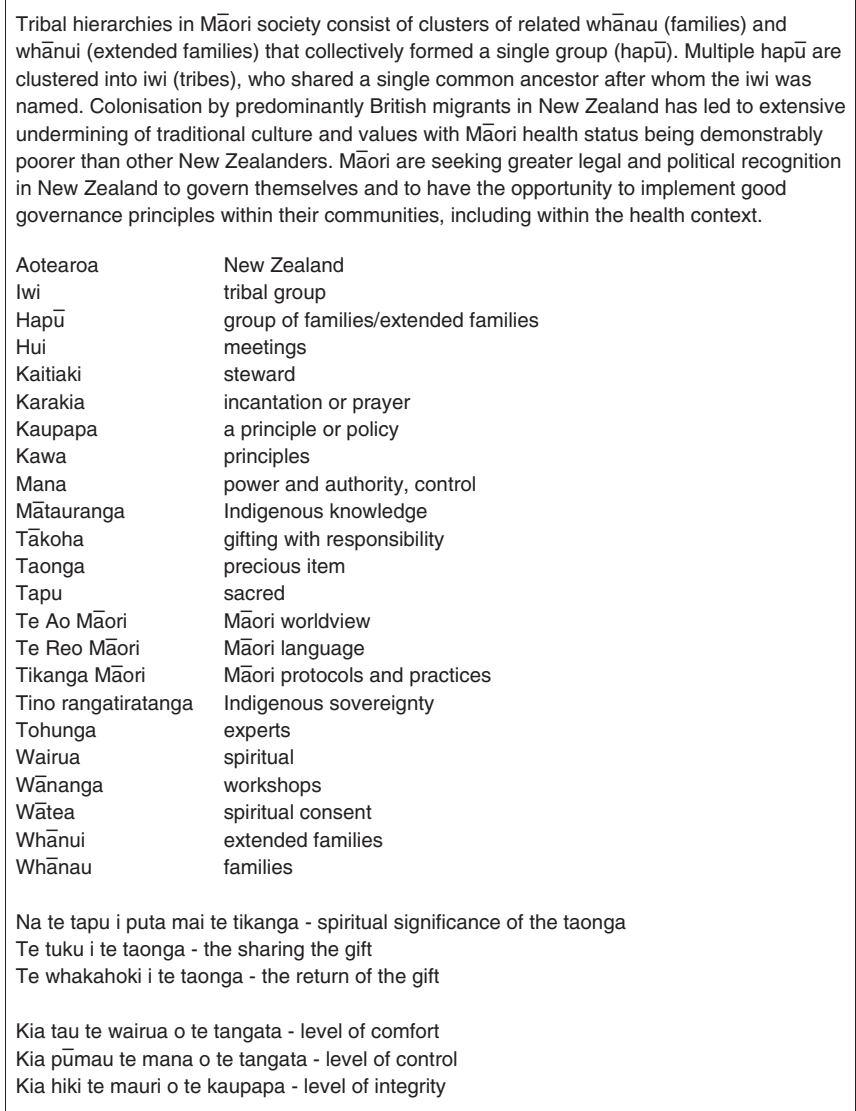

Figure 1 Brief outline of Māori society in Aotearoa, New Zealand.

sampling and to enhance the levels of transparency around the use of tissue samples.

Consideration of risk and benefit is of critical importance for Māori given the persistent pattern of health inequality observed across a wide range of health indicators. There is an expectation that ethical research practices will ensure that biomedical, clinical, and public health research will effectively contribute to Māori health development whenever possible. ${ }^{13}$ Therefore, increased dialogue between Māori and researchers is required to prioritize the genomic research agenda to increase the potential for community benefit. As a first step to achieving this goal, it is important to understand how biobanks can be more responsive to Māori concerns about research with human tissue.

\section{MATERIALS AND METHODS}

Te Mata Ira, a Health Research Council of New Zealandfunded research project to develop culturally informed guidelines for biobanking and genomic research, builds on Te Ara Tika, the best practice and ethical guidelines for health research involving Māori. ${ }^{13}$ A mixed-methods approach was utilized to collect data from a wide range of sources. Literature reviews, nine key informant interviews (five Indigenous, four Māori), five stakeholder workshops (three Māori-focused, two sciencefocused), five Iwi hui, and two wānanga with cultural experts were undertaken to explore the views of and implications for Māori participants (iwi and whānau). Culturally significant concepts and ideas were identified through these activities and analyzed iteratively by the research team over the course of the project.

Across the various data collection activities, the context of biobanking and genomic research was explained and key cultural concepts identified as relevant through literature and/or previous data collection activities were presented and provided a basis for discussions. The key question for the data collection activities was "What are the issues for Māori when participating in biobanking and genomic research?" The information that emerged from the discussions with participants was used to identify the core issues and themes represented within the model. ${ }^{14}$ A comprehensive feedback and iteration process involving another five Iwi hui, seven workshops, and nine presentations to researchers and communities was conducted. An international Indigenous advisory group and feedback from presentations to Indigenous communities in Australia, the United States, and Canada also contributed to an iterative analysis of the data and refinement of the model.

\section{RESULTS}

In the context of biobanking, Māori view the tissue sample, DNA, and associated data (genomic/clinical) as a taonga (precious item), which is tapu (sacred) and, therefore, subject to restriction. In a traditional context, the taonga would be the responsibility of a kaitiaki (steward) who would monitor access to and use of a specific taonga. Māori values as they relate to taonga should inform policy and practice within all spheres of biobank activities (operational, governance, and community engagement), for example, in the day-to-day collection and disposal of biospecimens, ${ }^{15}$ governance over the future use of biospecimens and data, ${ }^{16,17}$ engagement with communities, ${ }^{18-21}$ and community consent/mandate in support of the biobank and research project(s). ${ }^{22}$

To facilitate further Māori engagement in biobanking and to provide distinct opportunities to engage Māori communities in decision-making, several key themes identified by Māori were highlighted and need to be considered to ensure that biobanking policies, procedures, and practices are culturally acceptable. These key themes are outlined in the He Tangata Kei Tua relationship model (Figure 2). This model aligns with the key issues from the Te Mata Ira framework for genomic research with Māori ${ }^{14}$ and the Te Ara Tika framework for Māori research ethics. ${ }^{13}$ It considers their application to the sets of relationships that inform three spheres of biobank activity: operations, governance, and community engagement (including with Māori, clinical, and research communities).

\section{Operational activities}

Tikanga, or protocols for research with tissue, should address physical and spiritual components of consent reflecting the view that protocols arise to respond to the spiritual significance of the taonga (na te tapu i puta mai te tikanga). First, 


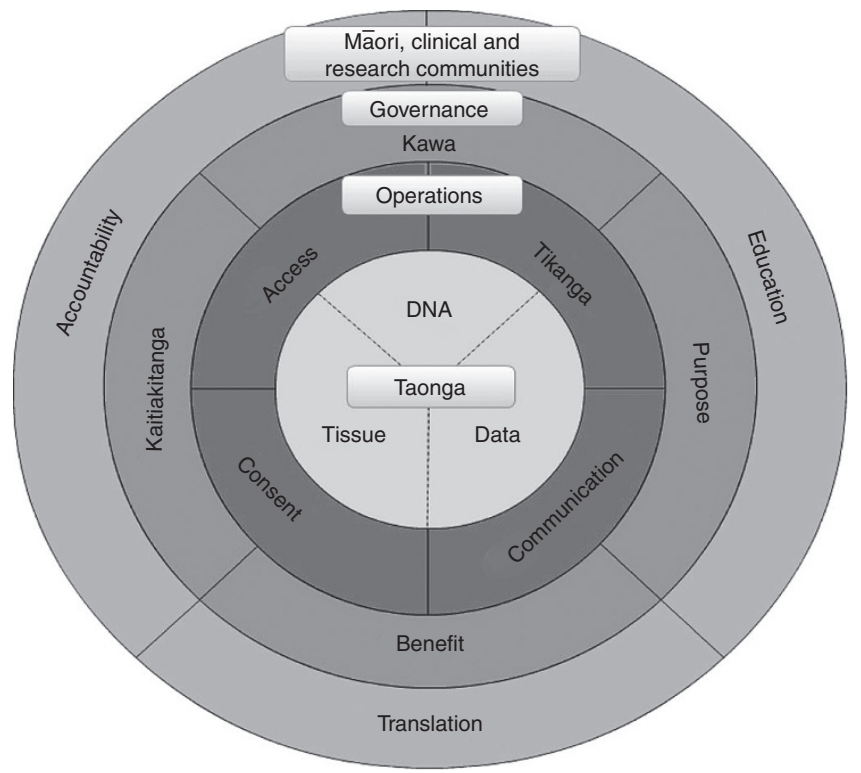

Figure 2 He Tangata Kei Tua relationship model for biobanking with Māori tissue.

te tuku i te taonga ("the sharing of the gift") involves establishing the relationship through consent. With this comes expectations of reciprocity, the need to define clearly the parameters of consent (conditions of consent, use of tissue, use of data, and benefit sharing), and the need to establish levels of comfort and safety for the participant and community. From a spiritual perspective, this may involve wātea (spiritual consent) and karakia or whakawātea (a form of karakia to remove a restriction) facilitated by access to tohunga (experts). Second, te hau o te taonga ("the spirit of the gift") takes into account the integrity of decisions about use and respect for the spirit in which the gift was given, and it adheres to consent parameters across the spiritual and physical aspects. The spiritual aspects can be addressed by assigning kaitiaki (guardians or stewards), maintaining regular communication and updates on use, and establishing living protocols (for example, a contractual obligation within a material transfer agreement that highlights the cultural significance of tissue and expectations of use). Physical aspects include the governance role, operating within consent parameters, and tracking and auditability for biospecimens and data. Third, te whakahoki i te taonga ("the return of the gift") requires expression of respect for the relationship, reporting on all uses and outcomes, the need to check on the satisfaction with process and outcomes, access to raw data and reports, re-consent for future use and participation, and providing opportunities to either re-consent or exit the research relationship.

Communication was identified as a key issue for Māori at an individual level and at a community level. There are multiple pathways for communicating progress to individuals and communities through active and passive channels (for example, letters, newsletters, or websites). Individual results should be communicated in an appropriate manner to participants, whānau, and general practitioners with due regard for issues of privacy and confidentiality. Incidental findings may have to go through a defined process to determine the level of significance and whether they are clinically actionable. In such cases, access to genetic counseling should be facilitated and issues of risk for biological relatives should be discussed.

Scope and specificity of the consent are key considerations from a Māori perspective (and may include broad unspecified use, disease-specific use, unspecified use, specific project use, use for genetic/genomic analyses, access to clinical records, and/or use for possible commercialization). Similarly, return of results (research, individual, and incidental findings), anonymization of biospecimens, putting genomic information on open data sharing platforms, and timing of consent (for example, relating to clinical trial/substudy/future use) are other important considerations. Participants indicated a preference for "consent for every use"; however, more open consents for future use were acceptable when balanced by effective Māori representation within the governance structures of the biobank.

Iwi expected to be consulted-to gain collective consentabout projects that would use biospecimens from their communities. Biospecimens and data should be used with due regard to the individual donors, and Iwi consent should be sought to ensure research that supports Māori health priorities. Communities should be acknowledged when their data are included in secondary studies, and there is an expectation that study results from any secondary use of their biospecimens or data will be communicated back to communities. In this way, re-contact options may facilitate re-consent for secondary use because research organizations/biobanks should be accountable to the donors for their decisions regarding future use of biospecimens.

At the operational level, researcher-participant relationships should inform the eligibility of researchers to access tissues stored within a biobank. Based on previous negative experiences, ${ }^{23-25}$ Iwi have clear expectations of recourse for unethical researcher behavior and culturally insensitive research that may include blocking future access by researchers to biospecimens stored within a biobank. It may be beneficial for biobanks to explore different types of relationships with researchers, as preferred by other Indigenous peoples, ${ }^{26,27}$ and to establish more formal agreements or contracts to protect against this type of outcome. Research contracts or partnership agreements to prevent the use of biological samples or dissemination of information without the explicit consent of communities could ameliorate risks associated with the interpretation of data in ways that stigmatize or undermine oral histories. Furthermore, it may be beneficial for biobanks to explore with Iwi the different types of arrangements with donors, including ownership, custodianship, the fiduciary relationship, models of consent (broad, informed, dynamic), and mixed models (consent/fiduciary and consent/contract). Other types of relationships between donors and biobanks could also be considered; for example, individuals may be viewed as members of a biobank rather than as donors of biospecimens. 


\section{ORIGINAL RESEARCH ARTICLE}

\section{Governance activities}

There are four key areas of the governance sphere within which key issues of relevance to Māori may be considered: kawa (principles), kaitiakitanga (guardianship), purpose, and benefit (see Figure 2).

Respect for kawa (principles) of research with human tissue emerged as a key issue for Iwi. First and foremost, tissue is taonga (precious) and therefore tapu (sacred/restricted), and, by extension, so are the DNA and genomic data as representations of tissue. Commonly, the only decision that a donor makes is whether or not to donate a biosample to a biobank. The donation of a biosample is akin to the traditional concept of tākoha, in which the gift refers to the responsibility to look after the taonga. Kawa reflect the principles that should be considered at every decision-making point to ensure that this responsibility is being met within a biobank's range of activities. The kawa or principles identified through the Te Mata Ira project and endorsed by a wide range of Iwi and Māori stakeholders are (i) kia tau te wairua o te tangata (level of comfort), (ii) kia pūmau te mana o te tangata (level of control), and (iii) kia hiki te mauri o te kaupapa (level of integrity). Several possible ways of ensuring appropriate levels of comfort, control, and integrity for Māori are outlined here.

Guardianship supports the spirit of the gift and implies respectful conduct in relation to the use of biospecimens and all forms of data/information. Indeed, individuals and communities expressed the desire to retain veto rights over how their biospecimens and data are used, and this needs to be considered by biobanks at both the governance and operational levels.

Although Māori recognize the importance of efficient research processes that expedite potential future health benefits arising from collaborative research, there is also recognition of the need for data-sharing procedures to provide for Māori oversight of research. For Māori, data are a representation of tissue. Genetic information is a highly valuable strategic asset and, as for other indigenous populations, ${ }^{17}$ there are concerns about unfettered use by researchers. Although data-sharing policies aim to maximize public benefit derived from genetic studies by increasing research efficiency and the use of a pooled data resource for future studies, broad access to data has not historically led to benefits for indigenous populations. Māori have ownership interests in their data, and there is an increasing expectation that they will have some degree of control or influence over the use of raw data and how it might be linked with other datasets across different domains. It is possible to address the kawa (principles) that have been developed in the context of data. The wairua (spiritual) aspects of data as they relate to the level of comfort can be managed through governance procedures and effective communication. The mana (control) aspects of data can be addressed by assigning management and access rights to Māori. Processes of anonymization tend to remove the possibility of maintaining mana and limit opportunities to provide direct benefits to participants and their communities. As a consequence, processes to approve linking of data should be transparent to enhance mauri (integrity) and trust in the system. Ideally, data sharing (for secondary use and open platforms) should only occur with the participant's consent and, at an overall project level, mandated by representatives from the community.

A key discussion with Māori stakeholders in relation to biobanks is about purpose. The purpose of the biobank, its intended outcomes, and the team will all contribute to the level of comfort that a community has in a biobank. Māori will look more favorably on biobanks that support research projects designed to tackle Māori health priorities. It is also important to Māori that biobanks are clear about the range of studies or limitations on studies that the biobank will support. For biobanks, a clear communication plan and policy that facilitates meaningful engagement with Māori at the governance and operational levels are important.

Participants agreed that the benefits of any research project should outweigh the risks to Māori and that the biobank should ensure that Mãori tissue only supports projects that will potentially benefit Māori donors and their communities. Research has a range of outcomes, and part of the ethical deliberation involves considering the nature of the outcomes (risk versus benefit, short versus long term) and their relative distribution (researchers, participants, communities, society). Although researchers usually benefit from being involved in research, biobanks should consider how donors and their communities might also benefit. Equity and justice are ethical principles underpinning the importance of benefit-sharing, and Iwi highlighted that this might include capacity building and pathways for benefit sharing if commercialization opportunities arise.

Many times the benefits of research are poorly defined, indirect, or realizable over the long term, whereas possible harms such as stigmatization of small, readily identifiable communities are more immediate. ${ }^{17,28}$ It is noted that many Māori may be willing to participate in research if it is clearly connected to promoting wellness in communities or addressing specific health concerns of importance to Māori; with appropriate tribal oversight, many Mãori also support research whereby benefits are directed toward future generations. It is possible to develop within the health research system policy and process reinforcing "loops" to ensure that this occurs, for example, with Māori governance of biobanks as a first priority, and Iwi consultation and oversight of projects seeking access to biospecimens. Improvements can also be made regarding engagement with Māori in the areas of ethical review and funding application processes. $^{27}$

\section{Community engagement}

Accountability in this context relates to the relationship between the research team and communities that support or participate in the biobank activity or research. Despite negative history, some researchers and indigenous communities have developed mutually productive research partnerships. ${ }^{17,29-31}$ These partnerships often have used community-based participatory research methods to determine collaborative research priorities and procedures. This approach values communities 
as partners in all aspects of the research process and has the potential to reestablish trust and reorganize power relationships. ${ }^{32}$ Expectations for ongoing feedback and communication with participants and Māori communities are key ways for research teams to demonstrate accountability.

Samples and data should be utilized with due regard to donor consent and for studies that contribute to Māori health priorities. For example, a biobank policy for researcher access to biosamples should require communities to be acknowledged when their data are included in secondary studies, and communities should receive study results from any secondary use of their samples or data. Biobanks and research organizations are accountable to the participants and their communities for their decisions regarding future use of samples and for facilitating benefit-sharing mechanisms for commercialization opportunities. Re-contact options that facilitate re-consent for secondary use may be one avenue to demonstrate this responsibility.

Māori recognize that genomic research will become an increasingly important part of the health system in the future. Improving levels of genetic literacy among Māori communities and improving cultural literacy among science communities are necessary to ensure beneficial outcomes for Māori health. Gaining a better understanding of how genomic research translates to health interventions and of the steps for developing clinically relevant outcomes is important. Education programs $^{20}$ and resources for indigenous communities ${ }^{21}$ have had positive effects on participation levels and the level of comfort for biobanking and genetic research participants.

Knowledge translation informs resource allocation and can support service development. These are key outcomes for Māori communities from research. The challenge for genomic researchers is to articulate how genomic research translates to improved health outcomes across the spectrum of public health and personalized medicine. The relevance of the research results should be shared with participants and their communities, and clinically actionable results should be shared with clinicians and service providers using an ethically defensible plan.

\section{Grounding the He Tangata Kei Tua model: policy and practice implications}

Moving forward, priorities should include comprehensive policy and practice actions that create an enabling environment for Māori engagement in biobanking and genomic research with targeted actions that enable Māori to overcome barriers to participation. Policy assessments should be carefully designed toward the goal of culturally acceptable biobanking and genomic research.

The He Tangata Kei Tua model was reviewed during its development by two key groups: the Auckland Regional Tissue Bank, a biobank that is a collaboration between the University of Auckland and three Auckland District Health Boards, and the Research Advisory Group-Māori (RAG-M), whose role it is to evaluate research applications from a Māori perspective and provide cultural advice to researchers in the Capital and Coast District Health Board region. Two workshops were organized and purposed for ARTB and RAG-M to discuss Māori views of biobanking and to explore strategies and approaches that RAG-M and ARTB might adopt and/or present to groups with which they are working. To prompt consideration of the policy and practice implications, the He Tangata Kei TuaRelationship Model for Biobanking was also presented, along with the cultural foundation developed by the Te Mata Ira research team.

Led by Shirley Simmonds, member of RAG-M, and Maui Hudson, the Principal Investigator of the Te Mata Ira research project, nine people attended the RAG-M workshop at Wellington Hospital on 12 November 2015. The participants included research nurses, Māori health service workers, students, and RAG-M members. Similarly, nine people attended the ARTB workshop at the University of Auckland on 21 August 2015. The participants included biobank managers, clinical researchers, and ARTB governance group members. Thematic analysis revealed questions and discussion aligned with each aspect of the relationship model for biobanks.

A key theme arising at each workshop was how accountability could be encouraged as part of the biobanking and research process in New Zealand. In line with themes from Iwi workshops about communication, policy mechanisms could be developed to focus on consultation and communication requirements between researchers, research institutes, Māori leadership, and communities:

1. Funders could include resources designated for consultation with Māori prior to and throughout the research period, as has been suggested elsewhere in the context of tribal data sharing. ${ }^{17}$

2. Grant proposals could require a comprehensive dissemination plan that specifies how researchers will provide information back to communities during the project period and following completion of the research, including resources for community meetings and travel to research and dissemination hui for Māori representatives and researchers.

3. A research partnership evaluation could be required as part of the project/funding application for the benefit of the research community, funding organizations and Māori by identifying the elements of collaboration that facilitate respectful relationships and support comfort, control, and integrity.

4. A Māori biobank or Māori process within an existing biobank could be established to provide for explicit Māori governance over tissue and to ensure that the risk related to cultural harms are adequately assessed from a Māori perspective. If tino rangatiratanga (indigenous sovereignty) is to achieve full effect within the policy domain, then Māori must have a well-established asset base, they must be in control of the decision-making process, including resource allocation, service delivery must address the diversities of Māori realities, and Māori must be the recipients of policy decisions made. ${ }^{33}$ 


\section{ORIGINAL RESEARCH ARTICLE}

5. Defining "research benefits" and "dissemination" (for funding and ethics application processes) may be useful to ensure that there is shared understanding of these terms so that communities can make more informed choices to balance participation and risk.

\section{DISCUSSION}

The He Tangata Kei Tua model is a holistic framework developed within a specific cultural positioning that integrates concepts including cultural principles, protocols, and preferences that are important to Māori. Although the model has focused on Māori aspirations in the New Zealand context, it provides a framework for considering cultural values in relation to other indigenous populations and society in general. The model has been presented to indigenous communities in Australia, Canada, and the United States. The concepts recognizing the cultural and spiritual significance of tissue resonated with these communities, as did the emphasis on enhancing participation in governance and improving processes of communication and feedback. Similarly, presentations to biobanking communities in New Zealand has elicited a strong support for the conceptual underpinnings of the model and generated discussion about the possibility of establishing Māori-led biobanks.

A general theme underpinning the model is the shift in the mode of engagement with Māori from benefit sharing to power sharing. ${ }^{34}$ The notion of power-sharing through participatory governance reinforces the idea that tissue is a taonga and is "on loan" to the research team and/or biobank. ${ }^{35}$ Emerging models of cogovernance associated with environmental commons $\mathrm{s}^{36,37}$ could be adapted to deal with the genomic commons. Similarly, questions about ownership, control, access, and possession (OCAP) created by First Nation communities in Canada are informing emerging debates on indigenous data sovereignty and the rights of tribal nations to determine how and for what the common genomic data of their members can be used. ${ }^{38,39}$ OCAP principles are an expression of First Nations jurisdiction over information about their communities and its community members. Data sharing has become a fundamental component of biorepository research; it will be important to develop novel ways to balance patient privacy with public utility and indigenous rights in different countries.

Maintaining public trust in the biorepository enterprise is essential because samples and data of a personal nature are being shared more widely, including among national and international consortia. Biorepositories have to become responsible stewards of both the physical samples and associated data, and the community-based principles suggested within this framework aim to ensure high levels of trust and accountability. Ensuring that research is focused on Māori is one pathway to addressing inequalities in health outcomes for Māori communities. Similarly, the level of Māori participation in biobanks will increase only if biobanks address the cultural dimensions associated with their activities and can demonstrate that Māori communities are receiving equitable benefits from their involvement. It also highlights the need for more participatory governance arrangements that influence operational activities and community engagement to encourage stronger relationships across Māori, clinical, and research communities.

\section{ACKNOWLEDGMENTS}

The Te Mata Ira research team extends sincere thanks and gratitude to the participants of Iwi-Ngāti Hine, Ngāti Whātua ki Orakei, Ngāi Tahu, Ngāti Porou, Ngāti Rakaipaaka-who generously participated in the project. Thanks to the scientists, researchers, and biobank managers who provided feedback on these ideas throughout the project. Finally, the authors thank the Health Research Council of New Zealand, which funded the research.

\section{DISCLOSURE}

The authors declare no conflict of interest. This work was funded by the Health Research Council of New Zealand.

\section{REFERENCES}

1. Baker M. Biorepositories: Building better biobanks. Nature 2012;486:141-146

2. Bahcall OG. Clinical whole-genome sequencing. Nat Rev Genet 2015;16:377.

3. McClellan KA, Avard D, Simard J, Knoppers BM. Personalized medicine and access to health care: potential for inequitable access? Eur J Hum Genet 2013;21:143-147.

4. Mclnnes RR. 2010 Presidential Address: Culture: the silent language geneticists must learn-genetic research with indigenous populations. Am J Hum Genet 2011;88:254-261

5. Organisation for Economic Co-operation and Development. OECD Guidelines on Human Biobanks and Genetic Research Databases, 2009. http://www.oecd. org/sti/biotech/44054609.pdf. Accessed 14 February 2016.

6. Mitchell D, Geissler J, Parry-Jones A, et al. Biobanking from the patient perspective. Res Involv Engagem 2015;1:4

7. Denny JC. Chapter 13: Mining electronic health records in the genomics era. PLoS Comput Biol 2012;8:e1002823.

8. McCusker ME, Cress RD, Allen M, Fernandez-Ami A, Gandour-Edwards R. Feasibility of linking population-based cancer registries and cancer center biorepositories. Biopreserv Biobank 2012;10:416-420.

9. McGuire AL, Beskow LM. Informed consent in genomics and genetic research. Annu Rev Genomics Hum Genet 2010;11:361-381.

10. Wolf SM, Crock BN, Van Ness B, et al. Managing incidental findings and research results in genomic research involving biobanks and archived data sets. Genet Med 2012;14:361-384.

11. Locock L, Boylan AM. Biosamples as gifts? How participants in biobanking projects talk about donation. Health Expect 2016; 19:805-816.

12. Fullerton SM, Anderson NR, Guzauskas G, Freeman D, Fryer-Edwards K. Meeting the governance challenges of next-generation biorepository research. Sci Transl Med 2010;2:15cm3.

13. Hudson M, Milne M, Reynolds P, et al. Te Ara Tika: a framework guideline about Māori research ethics for researchers and ethics committee members. Health Research Council of New Zealand: Auckland, New Zealand, 2010.

14. Hudson M, Beaton A, Milne M, et al. He Tangata Kei Tua: Guidelines for Biobanking with Māori tissue and Guidelines for Genomic Research with Māori. Māori and Indigenous Governance Centre, University of Waikato: Hamilton, New Zealand, in press.

15. Auckland District Health Board, 2003. Tikanga Recommended Best Practice. http://www.adhb.govt.nz/researchoffice/mrrc/tikanga_-_rbp.html. Accessed 14 February 2016

16. University of Auckland. (n.d.) Report of the University of Auckland Te Wai o Rona Project Review Team. University of Auckland Faculty of Medical and Health Sciences: Auckland, New Zealand.

17. James R, Tsosie R, Sahota P, et al.; Kiana Group. Exploring pathways to trust: a tribal perspective on data sharing. Genet Med 2014;16:820-826.

18. Pihama L, Cram F, Walker S. Creating methodological space: A literature review of Kaupapa Māori research. Can J Nativ Educ 2001;26: 30-43.

19. Smith, L. Decolonising Methodologies: Research and Indigenous Peoples. Zed Books: New York, 1998.

20. Kiviniemi MT, Saad-Harfouche FG, Ciupak GL, et al. Pilot intervention outcomes of an educational program for biospecimen research participation. J Cancer Educ 2013;28:52-59. 
21. National Congress of American Indians, American Indian and Alaska Native Genetics Resource Centre, 2016. http://genetics.ncai.org/for-tribes/. Accessed 21 March 2016.

22. Jones DJ, Bush PL, Macaulay AC. Beyond consent: respect for community in genetic research. eLS, 15 May 2014.

23. Ratuva S, Mead A (eds). Pacific Genes \& Life Patents: Pacific Indigenous Experiences \& Analysis of the Commodification \& Ownership of Life. Call of the Earth Llamado de la Tierra and the United Nations University of Advanced Studies: Wellington, NZ, 2007.

24. Perbal L. The 'warrior gene' and the Mãori people: the responsibility of the geneticists. Bioethics 2013;27:382-387.

25. Gillett G, Tamatea AJ. The warrior gene: epigenetic considerations. New Genet Soc 2012:31:41-53.

26. Toki VM. Biobanking - a contractual right? J Law Med 2016;23:1.

27. Beaton A, Smith B, Toki $V$, et al. Engaging Māori in biobanking and genetic research: legal, ethical and policy challenges. Int Indig Policy J 2015;6. http:// ir.lib.uwo.ca/iipj/vol6/iss3/1/.

28. Merriman T, Cameron V. Risk-taking: behind the warrior gene story. N Z Med J 2007:120:U2440.

29. Guilford P, Hopkins J, Harraway J, et al. E-Cadherin germline mutations in familial cancer. Nature 1998:392:402-405.

30. Hepi M, Foote J, Marino M, et al. "Ko wai hoki koe?," or "Who are you?": Issues of trust in cross-cultural collaborative research. Kotuitui 2007;2:37-53.

31. Pitama S, Wells JE, Faatoese A, et al. A Kaupapa Māori approach to a community cohort study of heart disease in New Zealand. Aust N Z J Public Health 2011;35:249-255.
32. Wallerstein N, Duran B. Community-based participatory research contributions to intervention research: the intersection of science and practice to improve health equity. Am J Public Health 2010;100(suppl 1):S40-S46.

33. Wihongi $\mathrm{H}$. Tino rangatiratanga in health policies and practises. Thesis, University of Waikato, New Zealand, 2010.

34. Winickoff, DE. From Benefit-sharing to Power-sharing: Partnership Governance in Population Genetic Research. JSP/Center for the Study of Law and Society Faculty Working Paper. University of California: Berkely, CA, 2008.

35. Arbour L, Cook D. DNA on loan: issues to consider when carrying out genetic research with aboriginal families and communities. Community Genet 2006;9:153-160.

36. Harris, R. The Changing Face of Co-governance in New Zealand-how are Ngai Tahu and Ngai Tuhoe promoting the interests of their people through power-sharing arrangements in resource management? Thesis, University of Canterbury, New Zealand, 2015.

37. Controller and Auditor-General. (2016). Principles for Effectively Co-governing Natural Resources. Wellington, New Zealand.

38. Schnarch B. Ownership, control, access, and possession (OCAP) or selfdetermination applied to research: a critical analysis of contemporary first nations research and some options for first nations communities. J Aborig Res 2004; 1:80-95.

39. Hudson M, Farrar D, McLean L. Tribal Data Sovereignty: Whakatohea Rights and Interests. In: Kukutai T, Taylor J (eds). Indigenous Data Sovereignty: Toward an Agenda. CAEPR Research Monograph Series. ANU Press: Canberra, New Zealand, 2016. 